Article

\title{
An Experimental Technology of Drying and Clean Combustion of Biomass Residues
}

\author{
Awf Al-Kassir ${ }^{1}$ (i), Pedro Coelho ${ }^{2}$, Justo García-Sanz-Calcedo ${ }^{3, *(\mathbb{D})}$, Francisco J. Moral ${ }^{3}$, \\ Raúl Kassir Al-Karany ${ }^{3}$ (i) and Talal Yusaf ${ }^{4}$ \\ 1 Department of Mechanical, Energy \& Materials Engineering, University of Extremadura, \\ 06006 Badajoz, Spain; aawf@unex.es \\ 2 Mechanical Engineering Department, University of Lisbon, 1049-001 Lisbon, Portugal; \\ pedro.coelho@tecnico.ulisboa.pt \\ 3 Department of Graphic Expression, University of Extremadura, 06006 Badajoz, Spain; \\ fjmoral@unex.es (F.J.M.); ralxkass@alumnos.unex.es (R.K.A.-K.) \\ 4 USQ International, University of Southern Queensland Toowoomba, Darling Heights, QLD 4350, Australia; \\ talal.yusaf@usq.edu.au \\ * Correspondence: jgsanz@unex.es; Tel.: +34-924-289-600
}

Received: 3 May 2018; Accepted: 29 May 2018; Published: 1 June 2018

\begin{abstract}
In the present study, the drying and combustion of solid biomass residues are developed. The combustion of the residues inside a boiler and a stove have been done. We used three types of solid biomass residues (i.e., cork, pine pellet and olive pomace). These residues have been dried by using screw dryers. Experimental installation has been used for a series of thermal drying tests of the residues by measuring the temperature inside the dryer and their moisture contents. A laboratory screw dryer was used to dry the olive pomace by using hot gases from a chimney of a biomass stove. Elemental and proximate analyses, as well as the higher heating value (HHV) of the raw materials, have been determined. In the experiments, moisture content variation of the residues and drying temperatures are obtained. These residues are dried several times under the same drying conditions to achieve the final moisture content rate. On the other hand, the temperature of combustion chamber of the boiler has been measured under different conditions. It has been found that by increasing hot gas temperature, the drying rate is increased. Finally, it has been found that the drying of these residues increases their calorific values and reduces the emissions.
\end{abstract}

Keywords: biomass residues; clean combustion; drying; experimental

\section{Introduction}

Biomass energy exploitation has been developed in recent years, according to the indications of the energetic policy plans of the European Union and the plan of renewable energies [1]. These plans set a target of taking renewable energy as a primary source, which has been fitted as an objective for the year 2020. A huge number of resources have been devoted to the energy exploitation of biomass in the latter years [2]. The use of biomass residues as non-pollutant fuels in combustion processes has an economical benefit and a social development of rural zones [3]. In addition, the use of these residues decreases the environmental impact by eliminating the remnants and decreasing the emissions of pollutants to the atmosphere. The contents of $\mathrm{Cl}, \mathrm{S}$ and $\mathrm{N}_{2}$ in biomass are much lower than those corresponding to the fossil fuels [4]. The use of biomass has a high benefit to the atmosphere that leads to a favorable $\mathrm{CO}_{2}$ balance, since the organic matter is able to retain more $\mathrm{CO}_{2}$ than that released by its combustion. The biomass can be obtained in a sustainable and renewable manner, where the consumption speeds of these residues are not faster than their producing speeds, giving a favorable 
$\mathrm{CO}_{2}$ balance [5]. The biomass should undergo a series of transformation processes before it is used as an energy source. These processes are: physical processes, such as grinding and drying; biochemical processes, such as alcoholic fermentation and anaerobic digestion; and thermochemical processes that yield carbon, liquid hydrocarbons and gases [6]. The treatment of biomass residues and their conversion technologies could be presented under four basic categories: direct combustion processes, thermochemical processes, biochemical processes and agrochemical processes. Thermochemical conversion processes can be subdivided into gasification, pyrolysis, supercritical fluid extraction and direct liquefaction [7].

To increase energy efficiency, improve energy production quality and reduce emissions during energy conversion, biomass residues must commonly be dried in industry by using rotary dryers and screw dryers [8]. The biomass is introduced in the dryer inlet point in parallel flow with hot gas or air, and is dried along the whole length of the dryer up to its exit point. The residence time of biomass is controlled by changing a rotational velocity of a screw. Therefore, the drying time can be suggested according to the final moisture content for each type of wet biomass [9].

There are a variety of dryer types in industry. One of them is a contact-type dryer that consists of a hollow cylinder: inside it, the products that need to be dried are mixed with the drying hot gas or air [10]. In direct contact dryers, the heat and the mass transfer between the products and the hot gas occur. These processes are more effective by using a series of pallets installed on the inner surface of a dryer cylinder [11]. On the other hand, the benefit of using pallets inside the dryer is that a uniform moisture content distribution of the dried product can be achieved [12].

Waje et al. developed experimental studies based on a drying process using a screw conveyor dryer, and studied mean residence time distribution in the screw conveyor dryer [13]. They found that by increasing the screw speed, the degree of mixing was increased, but the mean residence time was decreased. The flow speed in a screw conveyor dryer approached the speed of the plug flow as the feed rate was increased, whereas an increase in the screw speed resulted in a mixed flow [13]. The drying time can be controlled by varying the rotational velocity of the screw, while the discharge uniformity can be controlled by both the screw velocity and the product flow rate [14]. An experimental analysis of a biomass plant with a maximum power of 2.3 MW was studied by Gimelli et al. [15]. They observed that the integration of biomass with a steam power plant was achieved by combining the hot exhaust gases together with the biomass in the main combustion chamber of the plant, and showed that the efficiency of the energy conversion was much higher than that from incinerating Combustible Derived from Residues (CDR), and thus, wet biomass with high moisture content can be disposed of in a gasifier [15].

Aziz et al. developed an innovative study using a fluidized bed dryer with superheated steam and its integration into a gasification-combined cycle system power generation [16]. Zhang et al. evaluated the effects of various testing conditions on a top-lit forced-up-draft semi-gasifier cooking stove [17]. The investigation showed that using forced secondary air and more fuel tended to improve both thermal and gas emission performances. The ending points did not have significant effects on thermal efficiency and the carbon dioxide emission factor but did affect particulate matter emission. A relatively lower chamber height demonstrated a better performance on thermal metrics [17].

Gimelli et al. analyzed the experimental and numerical analysis of a biomass steam power plant with a maximum power of $2.3 \mathrm{MW}$, a maximum pressure of 48 bar and a turbine inlet temperature of approximately $430^{\circ} \mathrm{C}$ [18]. The analysis of the biomass power plant pointed out some critical issues could be summarized in three points: low plant efficiency due to the small size, biomass supply range and continuous variation of the operating point.

Biomass residues are still being used in heating applications and power generation $[19,20]$. Biomass fuels have numerous environmental advantages over fossil fuels [21], including the fact that the amount of $\mathrm{CO}_{2}$ emitted during the burning process is $90 \%$ less than that during the burning process of fossil fuels [22]. Cork, pine and olive pomace contain minimal amounts of sulfur and heavy metals, and they are not a hazard to acid rain pollution [23]. The higher heating values (HHVs) of 
these residues are between 17 to $20 \mathrm{MJ} / \mathrm{kg}$. Increasing moisture content of these residues decreases their HHVs. For large-scale combustors, such as fluidized bed combustors, the maximum acceptable moisture content of the residues is approximately $45 \%$. The higher and significantly fluctuating moisture content in wood causes unstable combustion, and higher $\mathrm{CO}$ and volatile organic compound emissions [24]. In gasification process, if the wood has high moisture content, the concentration of tar is higher and the heating value of the generated gases decreases. The biomass residues are widely used for power generation [25], while the study of the effect of moisture content on overall energy efficiency is limited [26]. Normally, raw biomass has $60 \%$ to $70 \%$ moisture content. Therefore, high moisture content reduces the efficiency of the solid fuel for direct combustion and produces tar in pyrolysis and gasification [27].

The integration of a drying process into a power station fuel system was investigated by other authors [28]. They used waste heat from a process industry plant as a heat source for drying. Panepinto et al. analyzed the environmental compatibility of a biomass plant with production of both electricity and heat in a small town in Piedmont (Italy) [29]. The pine chips with $60 \%$ moisture content were dried to be provided as the input fuel for a subsequent power plant. An aim of thermal drying is to reduce moisture content of the residues. In the drying process, the heat is transferred from hot fluid (gas) to the residues, and the mass transfer is processed from the residues to the hot gas simultaneously [30]. Many factors can be considered, such as the product nature, its different characteristics, the magnitude of the processes of heat and mass transfer, and finally, the periods and duration of the drying process [31]. The drying process can be divided into three periods: In the first one, the temperature of the wet product to be dried rises. In the second one, the superficial evaporation of the water adhered to the wet biomass is carried out to a point of "critical water content". In this period, the velocity of drying remains constant. Finally, the third drying period occurs, in which, the process is slowed down due to the absence of adherent water on the surface. As a whole, the temperature of the product approaches that of the drying air or gas [8], which was reached after a certain period of time, as shown in Figure 1.

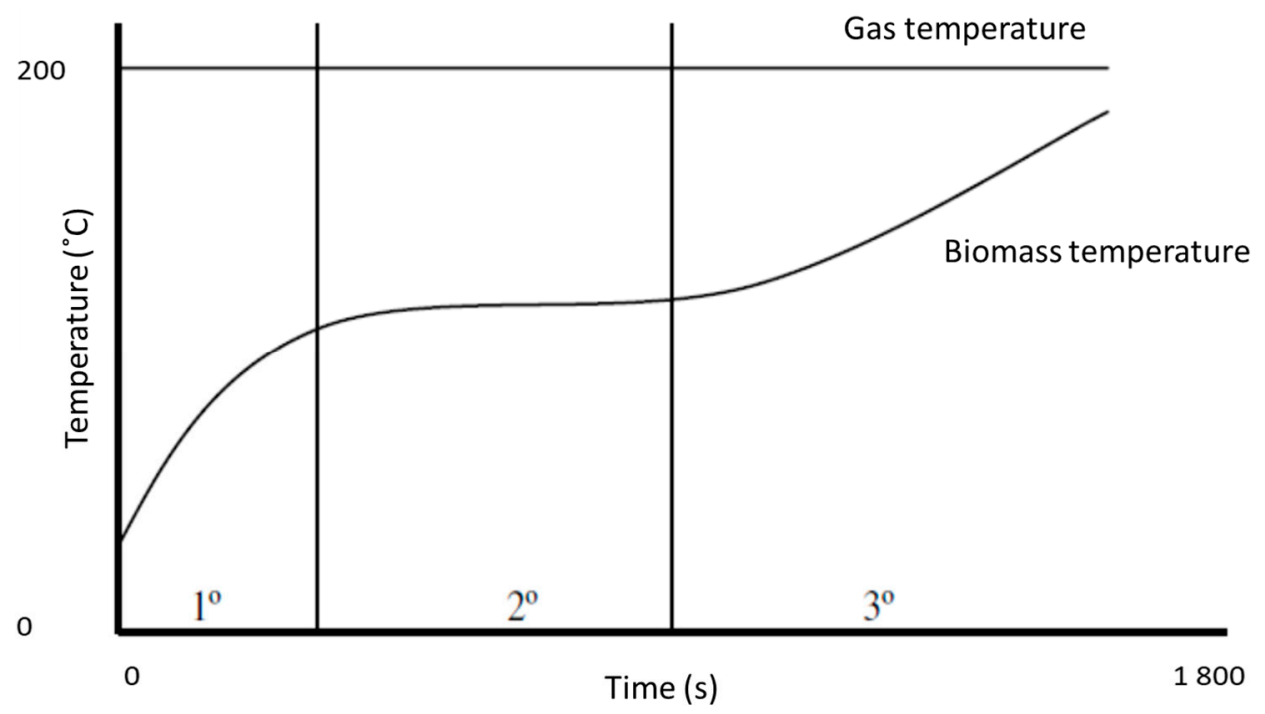

Figure 1. Temperature profile during the whole drying process [8].

There are various types of dryers [32] because of the huge variety of products and residues to process, the conditions imposed by the product to dry, the drying fluid and the material composing the dryer [33].

The aim of this research work was to develop an experimental technology of drying and clean combustion of biomass residues and the characterization of biomass residues for their use as a non-contaminant fuel. 


\section{Materials and Methods}

The energy equation of a thermal drying process can be written as a function of enthalpy change of the drying hot air or gas. The heat transfer rate $d Q(k W)$ from hot gas to the product or the biomass residue can be obtained as:

$$
d Q=\frac{d m_{\text {hotgas }}}{d t} \times\left(h_{\text {inlet }}-h_{\text {outlet }}\right)
$$

where $d m_{\text {hotgas }} / d t(\mathrm{~kg} / \mathrm{s})$ is the mass flow rate of drying hot gas, and $h_{\text {inlet }}$ and $h_{\text {inlet }}$ are the enthalpies of the drying gas at the inlet and the outlet of the dryer, respectively.

The same heat transfer rate can be written in terms of drying gas temperatures ( $\left.\mathrm{T}_{\text {hotgas }}\right)$ at inlet and outlet, as shown in Equation (2):

$$
d Q=\frac{d m_{\text {hotgas }}}{d t} \times C p_{\text {hotgas }} \times \Delta T_{m l g}
$$

where $C p_{\text {hotgas }}\left(\mathrm{kJ} / \mathrm{kg}{ }^{\circ} \mathrm{C}\right)$ is the medium heat capacity and $\Delta T_{m l g}\left({ }^{\circ} \mathrm{C}\right)$ is the log mean temperature difference across the dryer. Finally, from Equation (2), the necessary heat of the drying processes can be obtained.

In this study, the biomass has been firstly crushed and milled to size of $2-5 \mathrm{~mm}$. The chemical characterization of the samples was performed in order to determine the elemental composition (C, H, N and O) according to norm EN-15407:2011 [34]. The elemental analysis of these residues demonstrated the low contents of $\mathrm{S}$ and $\mathrm{N}$.

The determination of volatile matter, moisture, and ashes was performed following Spanish norms UNE-32019:84 [35], UNE-32001:81 [36], and UNE-32004:84 norms [37], respectively.

The HHV was determined with a Parr 1351 bomb calorimeter. The combustion parameters (i.e., $\mathrm{CO}, \mathrm{NO}, \mathrm{CO}_{2}, \mathrm{NOx}$, and $\mathrm{HC}$ contents in the fumes and temperature of the fumes) were analyzed by means of a Testo $300 \mathrm{M}-\mathrm{I}$ compact flue gas analyzer.

Temperatures in different points of the installation were measured with multiple thermometers. The results of the analysis were shown on a dry basis of $0 \% \mathrm{~S}$.

A drying of biomass has been carried out. In each drying experiment, moisture content of the dried residues has been measured using a gravimetric moisture analyzer equipment. In addition, the volatile compound, ash and fixed carbon amounts were analyzed in order to determine whether any emissions were releasing. It was found that $79.5 \%$ volatile compound, $18.9 \%$ fixed carbon and $1.6 \%$ ash were measured on a dry basis. According to these data, all samples including original ones had the same amount of the volatile organic compound. Therefore, it can be concluded that gas emissions during a drying process at an average of $180^{\circ} \mathrm{C}$ were negligible. This is due to the fact that when hot gas met wet biomass, the temperature inside the dryer droped immediately, and thus, no emissions were detected. The drying efficiency has been determined as a function of the temperature and the flow rate between the hot gas and solid residues inside the dryer.

In these experiments, we used exhaust gases for the drying of biomass with an average temperature of $180{ }^{\circ} \mathrm{C}$. The cylindrical housing of the dryer was made of a drawn steel pipe, with an inner diameter of $20 \mathrm{~cm}$ and a length of $100 \mathrm{~cm}$ (distance between inlet and outlet hot air pipes of the dryer). The outer diameter of the screw was $18 \mathrm{~cm}$ with $4 \mathrm{~cm}$ in pitch and $100 \mathrm{~cm}$ in length. A schematic of an experimental setup is shown in Figure 2. In these drying experiments, the process type was parallel flow.

Figure 3 shows that a direct-contact thermal screw dryer installation was used. Several experiments were carried out for the drying of biomass residues of $50 \%$ moisture content. There were two points to measure the temperatures of the inlet and outlet of the drying medium (hot gas). Other points were installed to measure the temperatures inside the dryer at different positions. 


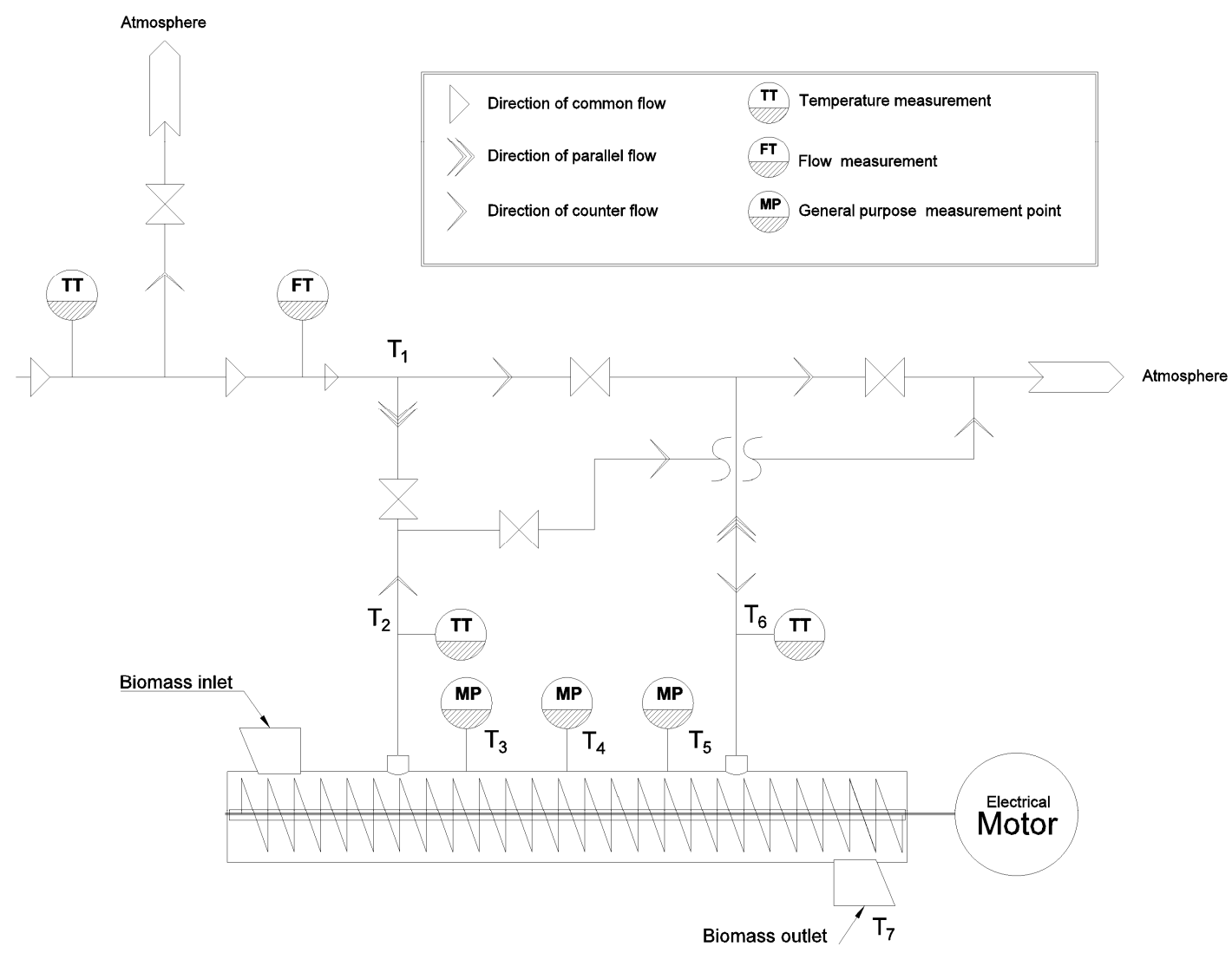

Figure 2. Schematic of an experimental setup. $\mathrm{T}_{1}$ : temperature of hot air; $\mathrm{T}_{2}$ : temperature of a hot gas chimney; $\mathrm{T}_{3}$ : temperature of a dryer gas inlet; $\mathrm{T}_{4}$ : temperature of first measurement point; $\mathrm{T}_{5}$ : temperature of second measurement point; $\mathrm{T}_{6}$ : temperature of a dryer gas outlet; and $\mathrm{T}_{7}$ : temperature of an olive pomace outlet.

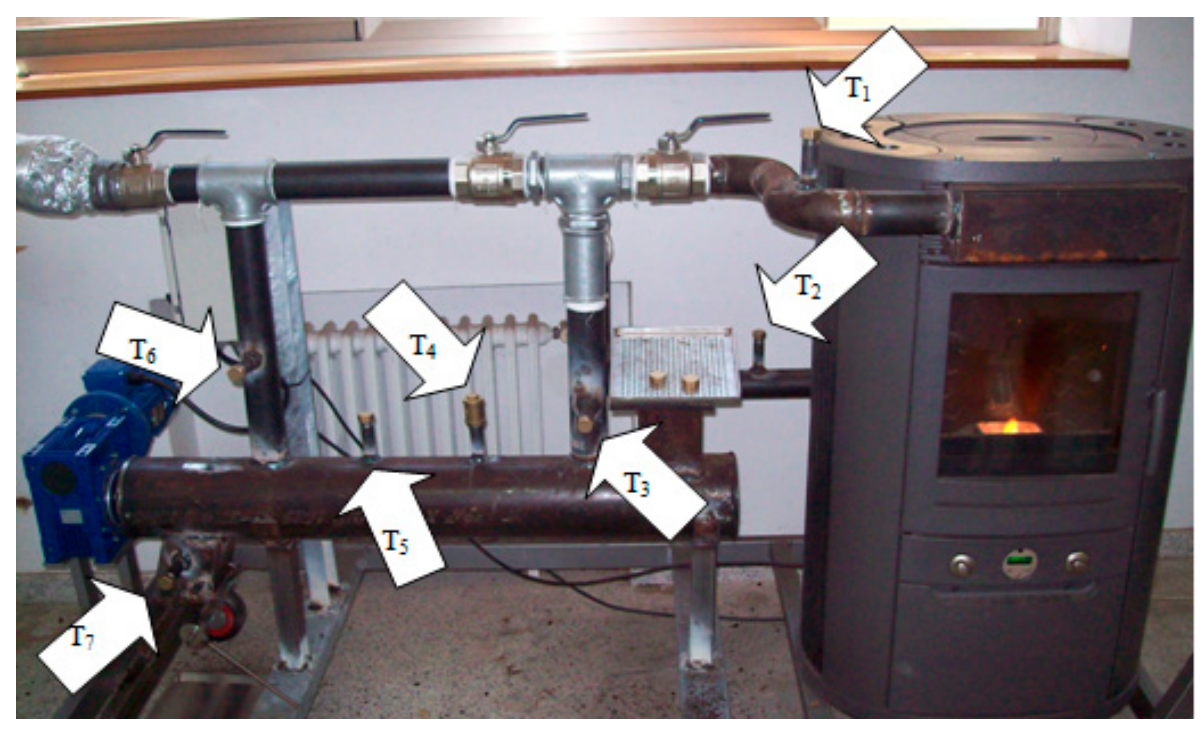

Figure 3. Laboratory experimental facility. $T_{1}$ : temperature of hot air; $T_{2}$ : temperature of hot gas chimney; $\mathrm{T}_{3}$ : temperature of a dryer gas inlet; $\mathrm{T}_{4}$ : temperature of first measurement point; $\mathrm{T}_{5}$ : temperature of second measurement point; $\mathrm{T}_{6}$ : temperature of a dryer gas outlet; and $\mathrm{T}_{7}$ : temperature of an olive pomace outlet. 
In addition, a set of experiments has been carried out for drying olive pomace. This was a byproduct of the olive oil production process that could be dried and used as a fuel in direct combustion. Its moisture content is almost $50 \%$. A small laboratory experimental facility was built and used to dry the olive pomace up to $10 \%$ of moisture content [38-40]. In these experiments, hot gases from the outlet of a chimney of a biomass stove were used as a drying medium. In these experiments, the olive pomace was dried four times in a screw dryer with an inner diameter of $20 \mathrm{~cm}$ and the length of $100 \mathrm{~cm}$. The rotation speed of the screw was selected to be $6 \mathrm{rpm}$ and the average hot gas temperature was $180{ }^{\circ} \mathrm{C}$ with a flow rate of $10 \mathrm{~m}^{3} / \mathrm{h}$.

On the other hand, a series of combustion experiments have also been carried out to determine boiler temperatures and flue gas emissions. The fuels used were biomass pellet (cork and pine). These residues were not torrefied. They have been analyzed through the determination of the immediate elementary analysis and the determination of their calorific value. Figure 4 shows a homogeneous combustion was observed in the combustion chamber of the boiler at a temperature of $280{ }^{\circ} \mathrm{C}$. On the other hand, temperatures of approximately $90{ }^{\circ} \mathrm{C}$ and $52{ }^{\circ} \mathrm{C}$ was observed in the external body of the boiler and the exhaust pipe of the fumes, respectively.

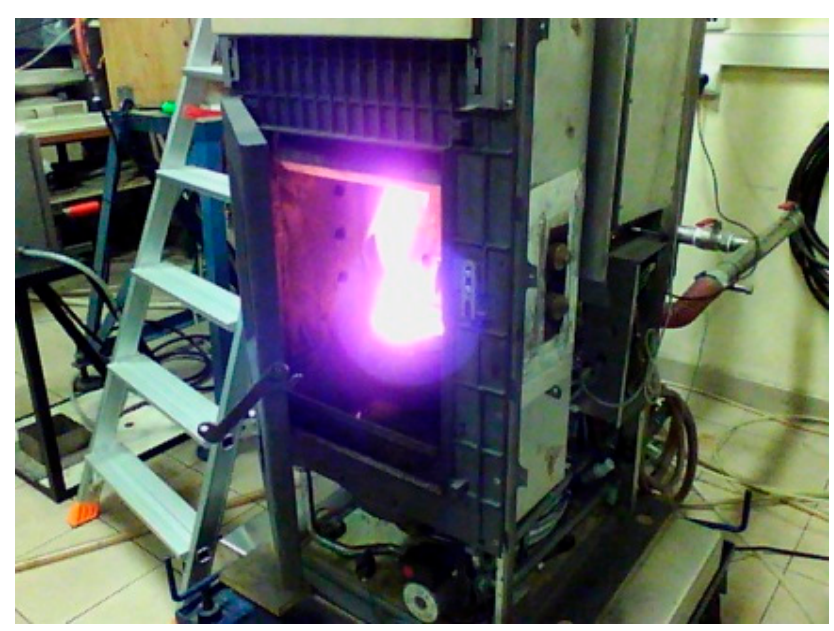

Figure 4. Biomass pellet combustion inside the boiler.

\section{Results and Discussion}

Table 1 shows the results obtained from the emissions produced in combustion tests realized on two types of biomass fuels which were pine and cork, by using a biomass boiler in order to evaluate the contamination of the fumes. It was observed that the emission levels are negligible in the type of biomass fuel, compared to other fuels. The yields of combustion experiments were $75.5-80.2 \%$ by using two types of dried pellets (Pine and Cork, Kihei, HI, USA). Figure 5 shows the heat transfer rate versus hot gas flow rate inside the dryer.

Table 1. Emissions from exhaust gases of biomass combustion.

\begin{tabular}{ccccccc}
\hline Type Pellet & $\mathbf{O}_{\mathbf{2}}(\mathbf{\%}$ vol.) & $\mathbf{C O}_{\mathbf{2}}(\mathbf{\%}$ vol.) & $\mathbf{C O}(\mathbf{p p m})$ & NOx $(\mathbf{p p m})$ & $\mathbf{H C}(\mathbf{p p m})$ & $\mathbf{T f}\left({ }^{\circ} \mathbf{C}\right)$ \\
\hline Pine & 17.4 & 3.2 & 10.7 & 17.5 & 2.2 & 126.7 \\
Cork & 16.4 & 3.7 & 383.4 & 72.5 & 13.8 & 135.6 \\
\hline
\end{tabular}




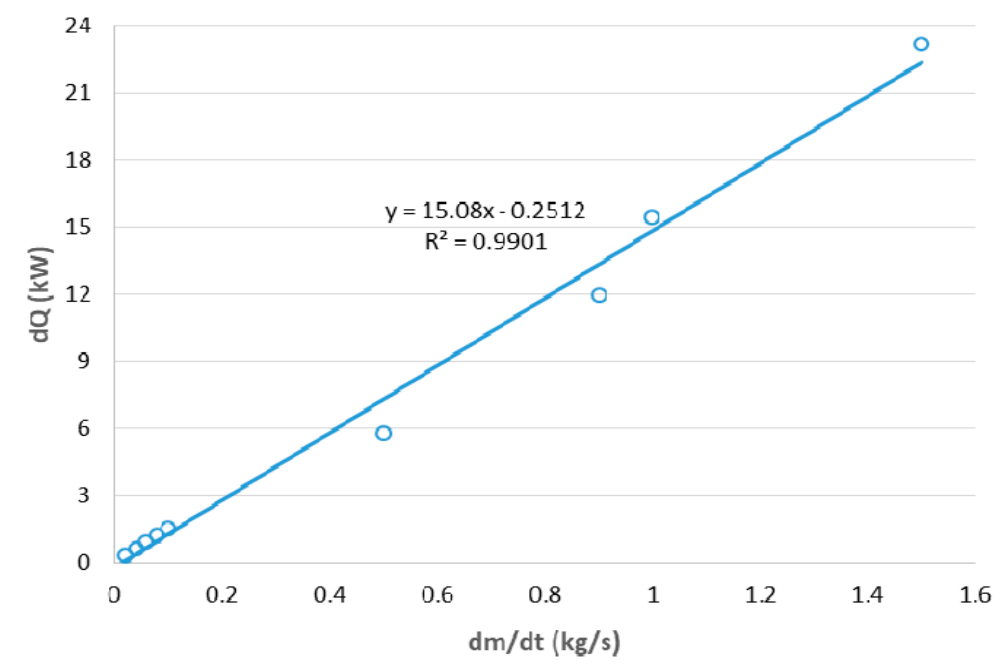

Figure 5. Heat transfer rate versus hot gas flow rate inside the dryer.

Figure 6 shows the temperature distribution inside the dryer in the case of olive pomace. The initial moisture content at the dryer entrance was 50\%. Five curves are plotted in Figure 6. One of them shows the temperature distribution in the empty dryer. The other four curves show the drying processes related to different time intervals within a period of one hour. The minimum moisture content for drying olive pomace obtained in these experiments was $10 \%$.

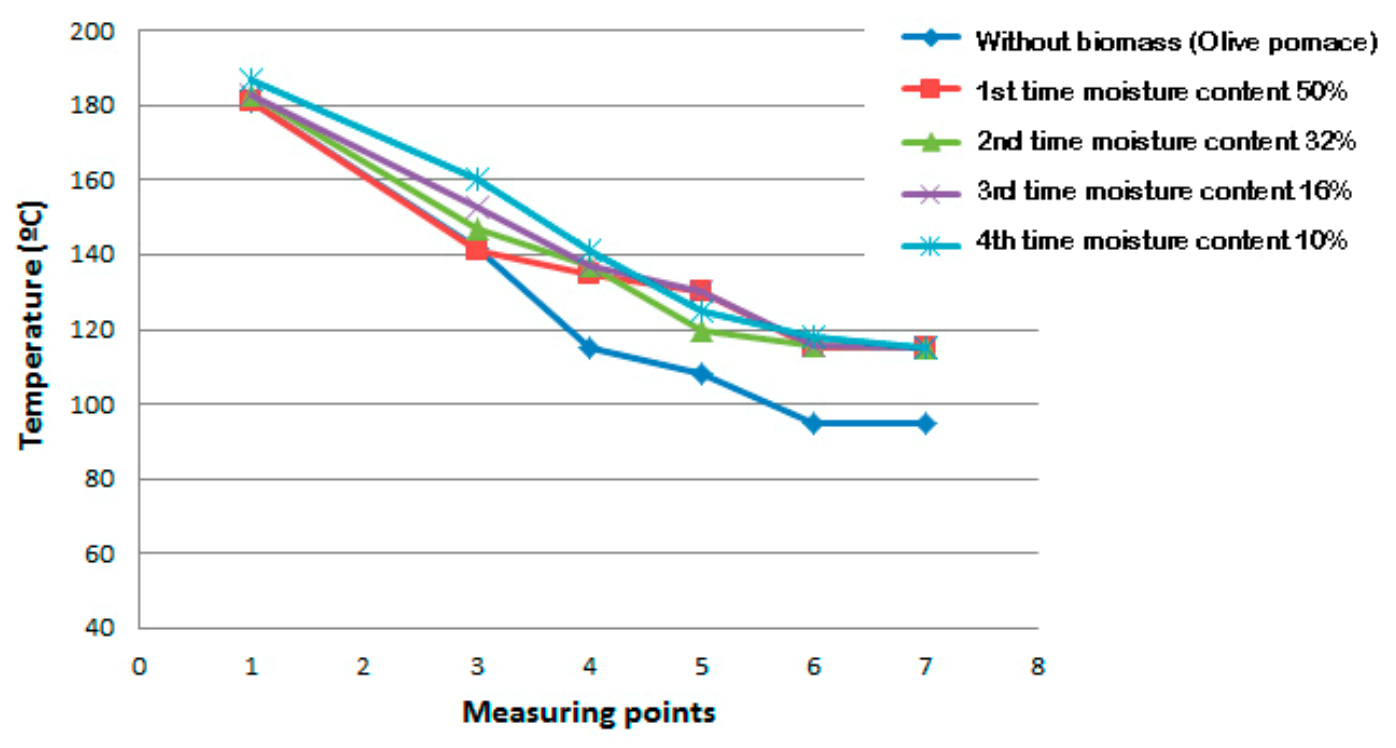

Figure 6. Temperature profile inside the dryer in the case of olive pomace.

It was observed that the temperature at the entrance first went down, and then it maintained almost constant along the dryer length. This was due to the fact that the heat losses at the entrance zone of the dryer reduced the temperature of gas. Afterwards, the drying velocity was unchanged with time, and the rate of drying was controlled by the rate of heat transferred to the evaporating surface. Thermal drying proceeded with diffusion of vapor from the saturated surface of the product into the hot gas inside the dryer. Therefore, the drying medium (hot gas) absorbed the humidity from the solid biomass by rejecting the latent heat of water vaporization. 


\section{Conclusions}

Characterization of biomass residues has been realized for the aim of their use as a non-contaminant fuel. It was found that the results of the present study were similar to those of the literature $[40,41]$. These authors studied the influence of the residue type and fuel mass flow rate on combustion parameters, resulting in combustion and drying yields of $80 \%$ and $47 \%$ respectively, when biomass residues were used under similar operating conditions of this study.

Experiments on thermal drying of solid biomass and olive pomace have been developed under various drying conditions. A screw dryer has been used in parallel flow between the residues and the drying medium. The dried biomass has been introduced in a boiler and a stove as a clean fuel for its combustion. The exhaust gases have been measured and analyzed, showing a very low emissions to the atmosphere. The obtained results indicated that these residues were dried several times in a screw-type dryer properly, reaching the lower moisture content of each residue. The temperature inside the dryer was observed stable while the flows along the dryer occurred. It could be related to the drying hot gas property that absorbed the moisture from the residues: In the first stage, no increase in temperature was observed. In the second stage, when all the moisture of the surface already disappeared, the temperature increased relatively up to the dryer outlet point. The experiments have been done under parallel flows between the residues and the drying medium. The drying air flow rate was fixed to $10 \mathrm{~m}^{3} / \mathrm{h}$. The average proper drying temperature of $180^{\circ} \mathrm{C}$ has been selected.

Author Contributions: Conceptualization, A.A.-K. and P.C.; data curation, J.G.-S.-C.; investigation, A.A.-K., P.C., J.G.-S.-C. and F.J.M.; software, R.K.A.-K.; supervision, T.Y.; writing of the original draft, A.A.-K. and J.G.-S.-C.; writing of review and editing, A.A.-K.

Acknowledgments: The authors would like to thank Regional Government of Extremadura for the supporting part of this research work realized by Awf Al-Kassir at IST in 2017. In addition, the authors wish to acknowledge Prof. Mario da Costa for lending his help in the laboratory and the European Social Fund for financial support. The present study has been carried out through Research Projects GR-18029 and 18086 linked to the VI Regional Plan for Research, Technical Development and Innovation from the Regional Government of Extremadura 2018-2020.

Conflicts of Interest: The authors declare no conflicts of interest.

\section{References}

1. Romero, S.R.; Santos, A.C.; Gil-Castro, M.A. EU plans for renewable energy. An application to the Spanish case. Renew. Energy 2012, 43, 322-330. [CrossRef]

2. Del Río González, P. Ten years of renewable electricity policies in Spain: An analysis of successive feed-in tariff reforms. Energy Policy 2008, 36, 2917-2929. [CrossRef]

3. Moreno, B.; Lopez, A.J. The effect of renewable energy on employment. The case of Asturias (Spain). Renew. Sustain. Energy Rev. 2008, 12, 732-751. [CrossRef]

4. Shinners, K.; Friede, J. Energy Requirements for Biomass Harvest and Densification. Energies 2018, 11, 780. [CrossRef]

5. Kadiyala, A.; Kommalapati, R.; Huque, Z. Evaluation of the Life Cycle Greenhouse Gas Emissions from Different Biomass Feedstock Electricity Generation Systems. Sustainability 2016, 8, 1181. [CrossRef]

6. Field, C.B.; Campbell, J.E.; Lobell, D.B. Biomass energy: The scale of the potential resource. Trends Ecol. Evol. 2008, 23, 65-72. [CrossRef] [PubMed]

7. Demirbas, A. Biomass resource facilities and biomass conversion processing for fuels and chemicals. Energy Convers. Manag. 2001, 42, 1357-1378. [CrossRef]

8. Al-Kassir, A.; Gañán, J.; Tinaut, F.V. Theoretical and experimental study of a direct contact thermal screw dryer for biomass residues. Appl. Therm. Eng. 2005, 25, 2816-2826. [CrossRef]

9. Roos, C.J. Biomass Drying and Dewatering for Clean Heat $\mathcal{E}$ Power; Northwest CHP Application Center: Olympia, WA, USA, 2008.

10. Zabaniotou, A.A. Simulation of forestry biomass drying in a rotary dryer. Dry. Technol. 2000, 18, 1415-1431. [CrossRef] 
11. Liu, Y.; Aziz, M.; Kansha, Y.; Bhattacharya, S.; Tsutsumi, A. Application of the self-heat recuperation technology for energy saving in biomass drying system. Fuel Process. Technol. 2014, 117, 66-74. [CrossRef]

12. Svoboda, K.; Martinec, J.; Pohorely, M.; Baxter, D. Integration of biomass drying with combustion/gasification technologies and minimization of emissions of organic compounds. Chem. Pap. 2009, 63, 15-25. [CrossRef]

13. Waje, S.S.; Thorat, B.N.; Mujumdar, A.S. Study of residence time distribution in a pilot scale screw conveyor dryer. Dry. Technol. 2007, 25, 249-259. [CrossRef]

14. Waje, S.S.; Thorat, B.N.; Mujumdar, A.S. Hydrodynamic characteristics of a pilot scale screw conveyor dryer. Dry. Technol. 2007, 25, 609-616. [CrossRef]

15. Gimelli, A.; Luongo, A.; Amoresano, A. Experimental Data and Thermodynamic Analysis of Biomass Steam Power Plant with Two Different Configurations Plant. Int. Rev. Mech. Eng. 2012, 6, 1109-1116.

16. Aziz, M.; Prawisudha, P.; Prabowo, B.; Budiman, B.A. Integration of energy-efficient empty fruit bunch drying with gasification/combined cycle systems. Appl. Energy 2015, 139, 188-195. [CrossRef]

17. Zhang, Y.; Zhang, Z.; Zhou, Y.; Dong, R. The Influences of Various Testing Conditions on the Evaluation of Household Biomass Pellet Fuel Combustion. Energies 2018, 11, 1131. [CrossRef]

18. Gimelli, A.; Luongo, A. Thermodynamic and experimental analysis of a biomass steam power plant: Critical issues and their possible solutions with CCGT systems. Energy Procedia 2014, 45, 227-236. [CrossRef]

19. García-Sanz-Calcedo, J.; Cuadros, F.; López, F. Eficiencia de una caldera de biomasa en un centro hospitalario. Aprovechamiento de huesos de aceitunas triturados para producción de calor. Dyna 2011, 86, 343-349. [CrossRef]

20. García-Sanz-Calcedo, J.; López-Rodríguez, F. Analysis on the Performance of a High Efficiency Administrative Building in Spain. Int. J. Green Energy 2017, 14, 55-62. [CrossRef]

21. Soltero, V.M.; Chacartegui, R.; Ortiz, C.; Lizana, J.; Quirosa, G. Biomass District Heating Systems Based on Agriculture Residues. Appl. Sci. 2018, 8, 476. [CrossRef]

22. Ståhl, M.; Granström, K.; Berghel, J.; Renström, R. Industrial processes for biomass drying and their effects on the quality properties of wood pellets. Biomass Bioenergy 2004, 27, 621-628. [CrossRef]

23. Li, H.; Chen, Q.; Zhang, X.; Finney, K.N.; Sharifi, V.N.; Swithenbank, J. Evaluation of a biomass drying process using waste heat from process industries: A case study. Appl. Therm. Eng. 2012, 35, 71-80. [CrossRef]

24. Madhlopa, A.; Ngwalo, G. Solar dryer with thermal storage and biomass-backup heater. Solar Energy 2007, 81, 449-462. [CrossRef]

25. Tolga-Balta, M.; Dincer, I.; Hepbasli, A. Development of sustainable energy options for buildings in a sustainable society. Sustain. Cities Soc. 2011, 1, 72-80. [CrossRef]

26. Faulkes, D.M. Modelling the optimum thermal store and biomass boiler size for a small communal heating scheme. Build. Serv. Eng. Res. Technol. 2015, 37, 136-147. [CrossRef]

27. Damartzis, T.; Michailos, S.; Zabaniotou, A. Energetic assessment of a combined heat and power integrated biomass gasification-internal combustion engine system by using Aspen Plus. Fuel Process. Technol. 2012, 95, 37-44. [CrossRef]

28. Bridgwater, A.V. Renewable fuels and chemicals by thermal processing of biomass. Chem. Eng. J. 2003, 91, 87-102. [CrossRef]

29. Panepinto, D.; Viggiano, F.; Genon, G. Analysis of the environmental impact of a biomass plant for the production of bioenergy. Renew. Sustain. Energy Rev. 2015, 51, 634-647.

30. Lleida, J.P.M. La Madera y su Secado Industrial; OIKOS-TAU: Barcelona, Spain, 1991.

31. Al-Kassir, A. Characterization and preparation of biomass residues. In Energy and Development, Summer International Course; SP-UEX: Caceres, Spain, 2001.

32. Brammer, J.G.; Bridgwater, A.V. Drying technologies for an integrated gasification bio-energy plant. Renew. Sustain. Energy Rev. 1999, 3, 243-289. [CrossRef]

33. Fagernäs, L.; Brammerb, J.; Wiléna, C.; Lauerc, M.; Verhoeffd, F. Drying of biomass for second generation synfuel production. Biomass Bioenergy 2010, 34, 1267-1277. [CrossRef]

34. Norm EN 15407:2011. Combustibles Sólidos Recuperados. Métodos Para la Determinación del Contenido en Carbono (C), Hidrógeno (H) y Nitrógeno (N); AENOR: Madrid, Spain, 2011.

35. Norm UNE 32019-84. Combustibles Minerales sólidos: Determinación del Contenido en Materias Volátiles; AENOR: Madrid, Spain, 1999.

36. Norm UNE 32001-81. Hulla y Antracita: Determinación de la Humedad Total; AENOR: Madrid, Spain, 1999.

37. Norm UNE 32004-84. Combustibles Minerales Sólidos: Determinación de Cenizas; AENOR: Madrid, Spain, 1999. 
38. Kassir Al-Karany, R. Characterization and Preparation of Biomass Residues with Experimental Thermal Drying \& Non-Contaminant Combustion. Master's Thesis, Polytechnic Institute of Portalegre, Portalegre, Portugal, 2013.

39. Al-Kassir, A.; Gañán, J.; González, J.F.; Kassir Al-Karany, R. Thermal drying of biomass by-products to obtain efficient environmental solutions with higher heating value and combustion efficiency. Curr. Opin. Biotechnol. 2013, S44. [CrossRef]

40. Al-Kassir, A.; Yusaf, T.; Kassir Al-Karany, R.; Hamawand, I. Determination of drying characteristics of biomass residues to be used as a renewable fuel. J. Biotechnol. 2015, 208, S15. [CrossRef]

41. Gonzalez, J.F.; Ledesma, B.; Alkassir, A.; Gonzalez, J. Study of the influence of the composition of several biomass pellets on the drying process. Biomass Bioenergy 2011, 35, 4399-4406. [CrossRef]

C 2018 by the authors. Licensee MDPI, Basel, Switzerland. This article is an open access article distributed under the terms and conditions of the Creative Commons Attribution (CC BY) license (http:/ / creativecommons.org/licenses/by/4.0/). 